\title{
MR imaging of the fetal brain
}

\author{
Orit A. Glenn
}

Received: 23 June 2009 /Revised: 22 October 2009 /Accepted: 26 October 2009 /Published online: 24 November 2009

(C) The Author(s) 2009. This article is published with open access at Springerlink.com

\begin{abstract}
Fetal MRI is clinically performed to evaluate the brain in cases where an abnormality is detected by prenatal sonography. These most commonly include ventriculomegaly, abnormalities of the corpus callosum, and abnormalities of the posterior fossa. Fetal MRI is also increasingly performed to evaluate fetuses who have normal brain findings on prenatal sonogram but who are at increased risk for neurodevelopmental abnormalities, such as complicated monochorionic twin pregnancies. This paper will briefly discuss the common clinical conditions imaged by fetal MRI as well as recent advances in fetal MRI research.
\end{abstract}

Keywords Fetal $\cdot$ MRI $\cdot$ Brain

\section{Introduction}

MRI is being increasingly used to evaluate the fetal brain, particularly when a fetus is at increased risk for neurodevelopmental disabilities or when an abnormality has been detected on prenatal US. Since its introduction in the early 1980s, studies have consistently shown that fetal MRI can detect abnormalities that are not apparent on prenatal sonography. Moreover, the identification of abnormalities by fetal MRI can influence decisions made about pregnancy management and delivery.

Fetal MRI offers several advantages over prenatal US. It has higher contrast resolution, is not affected by the

O. A. Glenn ( $\bowtie)$

Department of Radiology, Neuroradiology Section,

University of California, San Francisco,

505 Parnassus Ave., Rm. L358,

San Francisco, CA 94143, USA

e-mail: orit.glenn@radiology.ucsf.edu shadowing from the calvarium or by low amniotic fluid volume, and can be easily performed using commercially available ultrafast T2-W sequences. However, fetal MRI is limited by fetal motion, the small size of the structure being imaged, and the marked distance between the receiver coil and the structure being imaged. Therefore, fetal MRI is typically not performed before 22 gestational weeks.

Because the fetal brain is a dynamic structure, it is important for radiologists to familiarize themselves with the normal appearance of the fetal brain at different gestational ages in order to be better able to identify and characterize abnormalities with fetal MRI. There are several reviews of the topic [1-4].

\section{Fetal MR technique}

Fetal MRI is performed on 1.5-tesla MR scanner using a multi-channel phased array coil to allow increased coverage of the fetal head and increased signal-to-noise ratio. The mother lies supine during the course of the exam (typically 45-60 min). The mother is made as comfortable as possible during the MR exam in order to minimize fetal motion. If the mother is uncomfortable lying on her back (e.g., because of back pain or compression of the inferior vena cava), then the MR exam can be performed with the mother lying on her left side, although this results in lower image quality. At our institution, the mother is also kept NPO for $4 \mathrm{~h}$ prior to the MR exam in order to reduce fetal motion.

Because maternal or fetal sedation is not used, most fetal MRI is primarily performed using ultrafast T2-W sequences known as single-shot rapid acquisition with refocused echoes (i.e. single-shot fast spin-echo or half-Fourier acquired single-shot turbo spin-echo). Using these techniques, a single $\mathrm{T} 2-\mathrm{W}$ image is acquired in less than $1 \mathrm{~s}$, 
decreasing sensitivity to fetal motion. Because each image is acquired separately, motion will affect only the particular image that was acquired while the fetus moved. Typically, an initial localizer is obtained in three orthogonal planes with respect to the mother, using 6- to 8-mm thick slices with a 1to $2-\mathrm{mm}$ gap and a large field of view. The localizer is used to visualize the position of the fetus and determine fetal sidedness, as well as to ensure that the coil is centered over the region of interest. In certain cases, the coil needs to be repositioned in the middle of the examination, such as when switching from one twin to the other twin, or from the fetal brain to the fetal spine (such as in cases of Chiari II malformation). Typically, 3-mm thick ultrafast T2-W images of the fetal brain are then prescribed from the localizer with no skip. In cases of spine imaging, 2-mm thick slices are acquired because of the small structures being imaged. Images are acquired during maternal free breathing and in an interleaved fashion in order to reduce signal loss due to cross-talk between adjacent slices. Similar to pediatric neuroimaging exams, images are acquired in the axial, sagittal, and coronal planes. Typical imaging parameters are $\mathrm{TE}_{\mathrm{eff}}=90 \mathrm{~ms}, \mathrm{TR}=4,500 \mathrm{~ms}$, bandwidth $=25 \mathrm{kHz}$, matrix $=$ $192 \times 160$, number of excitations $=0.5$, and field of view $=$ $24 \mathrm{~cm}$, although certain parameters, such as field of view, need to be adjusted for increased maternal or fetal size or when aliasing artefact occurs.

Gradient echo-planar T2-W images are performed primarily to detect hemorrhage. Images are acquired in $7 \mathrm{~s}$, during a single maternal breath-hold, in the axial and coronal planes. Typical imaging parameters include $\mathrm{TR}=$ $5,290 \mathrm{~ms}, \mathrm{TE}=94$, flip angle $=90$, field of view $=30 \mathrm{~cm}$, matrix $=256 \times 256$, number of excitations $=1$, slice thickness $=$ $3 \mathrm{~mm}$, skip $=0 \mathrm{~mm}$. It is important to note that both hemorrhage and normal vessels appear hypointense on this sequence.

Fast multi-planar spoiled gradient-recalled acquisition in the steady state (FMPSPGR) T1-W images are acquired to detect hemorrhage, fat, or calcification. Images are acquired during a single maternal breath-hold with typical parameters of $\mathrm{TR}=120 \mathrm{~ms}, \mathrm{TE}=\mathrm{min}$, flip angle $=70$, field of $v i e w=24 \mathrm{~cm}$, matrix $=256 \times 160$, number of excitations $=1$, slice thickness $=$ $5 \mathrm{~mm}$, skip $=1 \mathrm{~mm}$, bandwidth $=31.25 \mathrm{kHz}$. Images are more susceptible to fetal motion because of their longer acquisition times and are of lower signal-to-noise image quality.

Advanced MR techniques such as diffusion-weighted imaging and parallel imaging have also recently been successfully applied to fetal MR imaging [5-8]. Diffusion-weighted imaging (DWI) provides quantitative information about water motion and tissue microstructure and can be used to identify focal areas of injury as well as to assess brain development. Single-shot echo planar diffusion-weighted images are acquired in $18 \mathrm{~s}$ during a single maternal breath-hold using the following parameters:
$\mathrm{TR}=4,500 \mathrm{~ms}, \mathrm{TE}=$ minimum, field of view $=32$, matrix $=$ $128 \times 128$, slice thickness $=5 \mathrm{~mm}$, skip $=2 \mathrm{~mm}$, bandwidth $=$ $167 \mathrm{kHz}$. Gradients are applied in three orthogonal directions using a $b$ value of $0 \mathrm{~s} / \mathrm{mm}^{2}$ and $600 \mathrm{~s} / \mathrm{mm}^{2}$. With increasing gestational age and engagement of fetal head in the pelvis, the amount of motion is decreased. Parallel imaging can also be applied to fetal MR imaging in order to decrease the scan time, increase image resolution, or decrease specific absorption rate. Because of their longer acquisition times, diffusion tensor MR imaging and MR spectroscopy are currently limited in their clinical application and are discussed in the Research Application section.

Some manufacturers have interactive scanning programs which allow the technologist to adjust certain scanning parameters (such as scan angle) in real time $[9,10]$. This is critical for obtaining true, non-oblique sagittal, axial and coronal images, which results in more accurate assessment of fetal brain structures and identification of abnormalities. As a result, overall image quality is improved and scan time is reduced.

\section{Clinical indications}

Fetal MRI is most commonly performed to evaluate a suspected abnormality detected by prenatal sonography. By further characterizing the finding and detecting additional abnormalities not seen on prenatal sonography, fetal MRI can provide information that can assist in prenatal counseling of the current pregnancy as well as counseling of the recurrence risk in future pregnancies. The most common indications for imaging the fetal brain will be briefly discussed below and include mild ventriculomegaly, suspected callosal agenesis, complications of monochorionic twinning, and posterior fossa abnormalities.

\section{Ventriculomegaly}

Ventriculomegaly is defined as atrial width equal to or greater than $10 \mathrm{~mm}$, measured at the posterior margin of the glomus of the choroid plexus on an axial image through the thalami [11]. Measurements of the atrial width on axial MR images have been published [12-14] and can differ by up to $1 \mathrm{~mm}$ to $2 \mathrm{~mm}$ compared to US [12]. When the ventricular atrium is measured in the coronal plane, US and MRI measurements are highly concordant [15].

Ventriculomegaly can be the result of developmental, destructive and obstructive processes, or a combination thereof. In cases of sonographically detected ventriculomegaly, fetal MRI is performed to detect any additional abnormalities, which might give insight into the etiology of the ventriculomegaly as well as neurodevelopmental outcome for the fetus. Fetal MR can detect additional 
abnormalities in up to $50 \%$ of cases of sonographically diagnosed ventriculomegaly [16-19]. These include agenesis of the corpus callosum, cortical malformations, periventricular heterotopia, cerebellar malformations, hemimegalencephaly, periventricular white matter injury, porencephaly, multicystic encephalomalacia, intraventricular hemorrhage, and germinal matrix hemorrhage [16-24].

The neurodevelopmental outcome of fetal ventriculomegaly is better when the ventricles are only mildly dilated, defined as measuring $\leq 15 \mathrm{~mm}$ in diameter [25-27]. Neurodevelopmental outcome is also better when no additional sonographic abnormalities and no genetic abnormalities are identified prenatally or at birth [26, 28-41]. When isolated mild ventriculomegaly is confirmed by fetal MRI, normal neurodevelopmental outcome has been observed in $94 \%$ of cases with ventricular size of less than $12 \mathrm{~mm}$ and in $85 \%$ of cases with ventricular size between $12 \mathrm{~mm}-15 \mathrm{~mm}$ [42]. Because of the known limitations of sonography in detecting brain abnormalities, fetal MRI is routinely performed when isolated mild ventriculomegaly is diagnosed by prenatal sonography in order to confirm the isolated nature of the ventriculomegaly.

Because fetal MRI can directly visualize the developing structures of the fetal brain (such as the ventricles, ventricular walls, germinal matrix, developing white matter, and cortex) and offers better tissue contrast compared to US, it allows improved identification of brain abnormalities that can occur in association with ventriculomegaly. Moreover, the detection of additional abnormalities by fetal MRI can give insight into both the etiology of the ventriculomegaly and neurodevelopmental outcome. When evaluating the brain in cases of isolated mild ventriculomegaly, the walls of the ventricles should be carefully examined for any areas of irregularity or nodularity that might indicate periventricular nodular heterotopia or subependymal hemorrhage. Periventricular nodular heterotopia appear as nodules along the margins of the lateral ventricles that are isointense to the germinal matrix (Fig. 1) and developing cortex; they cannot be distinguished from the subependymal nodules that occur in tuberous sclerosis, and so the brain parenchyma and heart should be evaluated for other stigmata of sclerosis tuberous when ventricular nodularity is seen (Fig. 2). Germinal matrix hemorrhage is best detected as an area of marked decreased signal on gradient EPI T2-W images. It might also appear as an area of decreased signal on SSFSE T2-W images in the ventricular germinal matrix, which may also appear abnormally thickened for the fetus' gestational age, or as an area of increased signal on T1weighted images (Fig. 3). Focal cysts in the region of the germinal matrix can result from prior germinal matrix hemorrhage, congenital infection, or certain metabolic disorders. The ventricles should also be evaluated for intraventricular hemorrhage, which can result in ventriculomegaly.

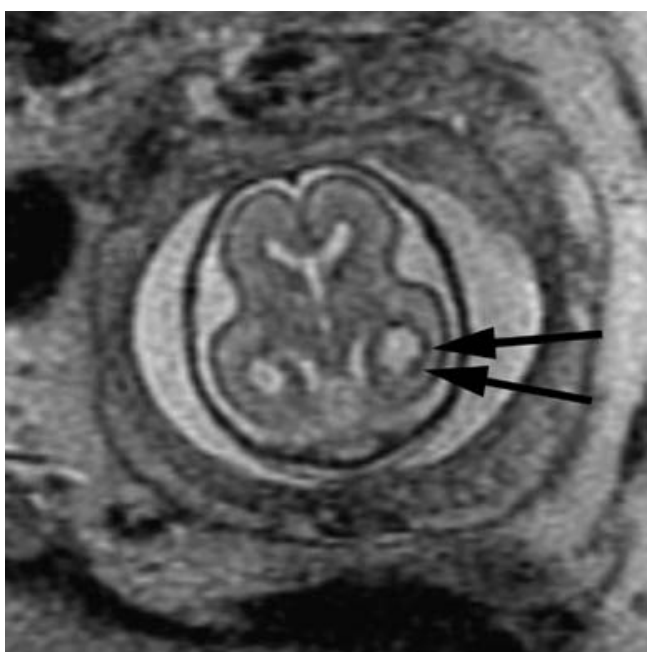

Fig. 1 Axial SSFSE T2-W image in a 22 gestational week fetus demonstrates several hypointense nodules along the margin of the left lateral ventricle (arrows). This was confirmed on coronal SSFSE T2$\mathrm{W}$ images (not shown) and is consistent with periventricular nodular heterotopia. (Reprinted with permission [2])

The developing white matter should also be carefully examined in cases of ventriculomegaly for evidence of diminished parenchymal thickness as well as destructive lesions. These lesions can appear as small, focal areas of increased signal on $\mathrm{T} 2-\mathrm{W}$ images in the developing white matter or as larger areas involving the overlying cortex as well (Fig. 4). More subtle irregularity of the ventricular margin might also be an indication of injury to the

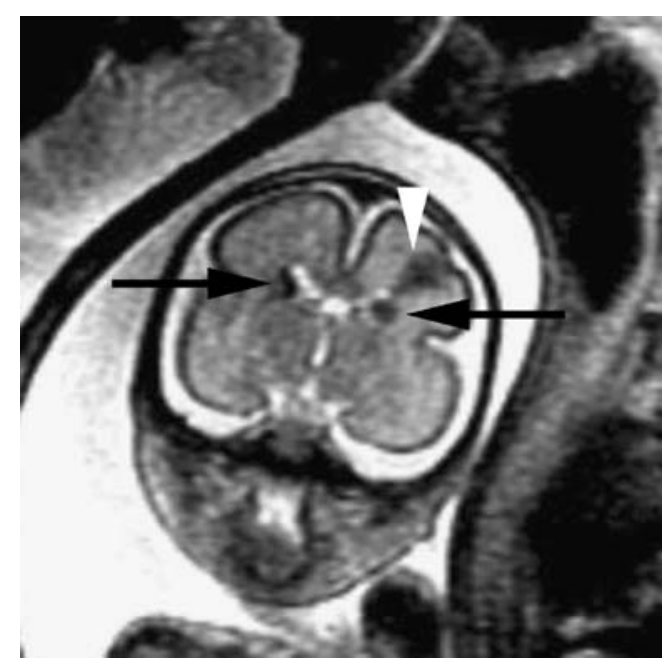

Fig. 2 Coronal SSFSE T2-W image in a 26 gestational week fetus demonstrates several hypointense nodules along the margins of both lateral ventricles (arrows), consistent with subependymal nodules; these are indistinguishable from periventricular nodular heterotopia (see Fig. 1). A hypointense wedge-shaped area is seen extending from the margin of the left lateral ventricle to the developing cortex (arrowhead), consistent with transmantle dysplasia. Findings are consistent with tuberous sclerosis. (Reprinted with permission [2]) 

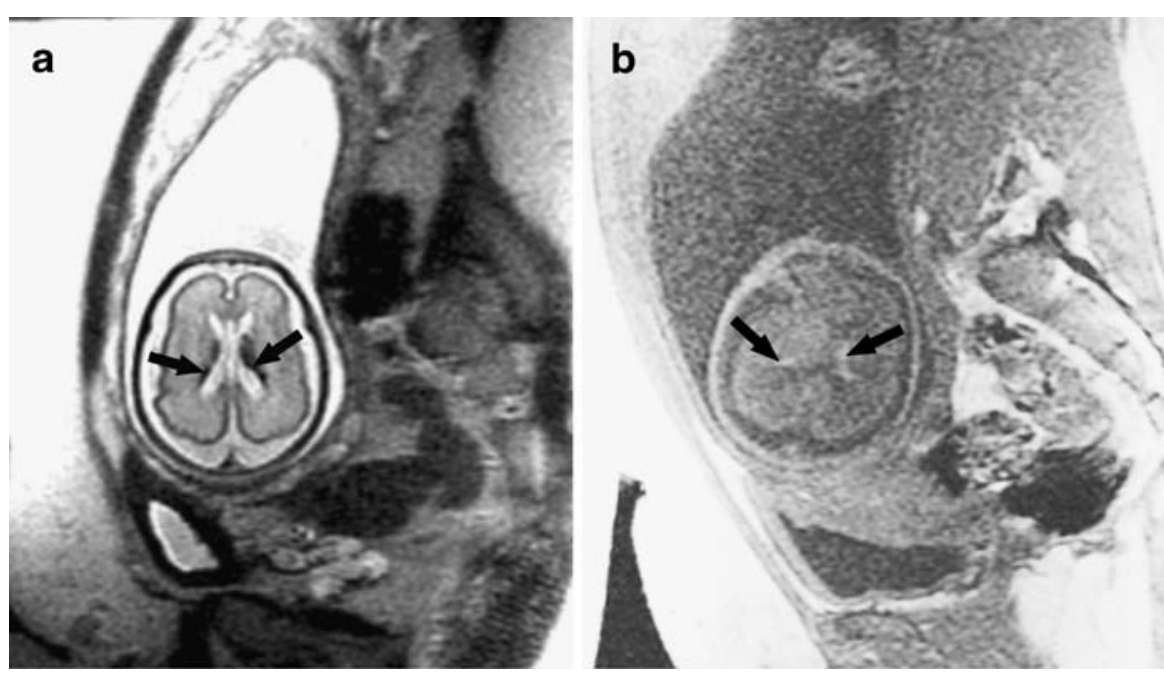

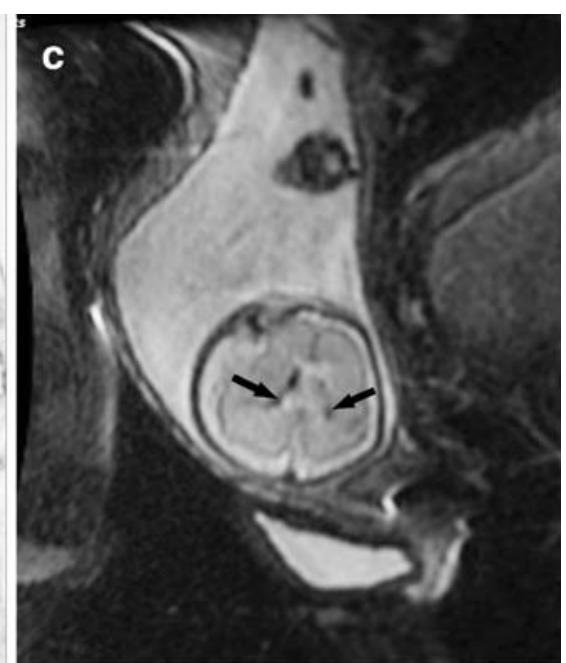

Fig. 3 Bilateral germinal matrix hemorrhages in a 28 gestational week fetus. a Axial SSFSE T2-W image demonstrates abnormal hypointensity in the germinal matrix (which also appears too thick), consistent with bilateral germinal matrix hemorrhages (arrows). b Axial FMPSPGR T1-weighted image demonstrates T1 hyperintensity

overlying developing white matter. Hemorrhages can also occur in the developing parenchyma, appearing as an area of marked decreased signal on gradient EPI T2-W images, decreased signal on SSFSE T2-W images, and increased signal on T1-weighted images, although the signal intensity can vary depending on the stage of hemorrhage (Fig. 4).

The corpus callosum should be directly visualized and measured on midline sagittal fetal MR images in all cases of ventriculomegaly, because sonographically diagnosed ventriculomegaly can actually be a result of abnormalities (which appears too thick) lining the lateral ventricles, also consistent with hemorrhage (arrows). c Axial echo-planar spin-echo T2-W image demonstrates marked hypointensity in similar regions, confirming the diagnosis of bilateral germinal matrix hemorrhages (arrows)

of the corpus callosum. More specifically, callosal hypogenesis or callosal agenesis can result in dilation of the posterior lateral ventricles (Fig. 5), leading to the appearance of isolated ventriculomegaly on prenatal sonography. Moreover, although the septal leaves (and therefore the cavum septum pellucidum) are absent in callosal agenesis, occasionally the anterior columns of the fornices mimic the septal leaves on prenatal sonography, giving the sonographic appearance of a normal cavum septum pellucidum when the cavum septum pellucidum is actually absent [43]. Although MRI can directly visualize the corpus callosum, it

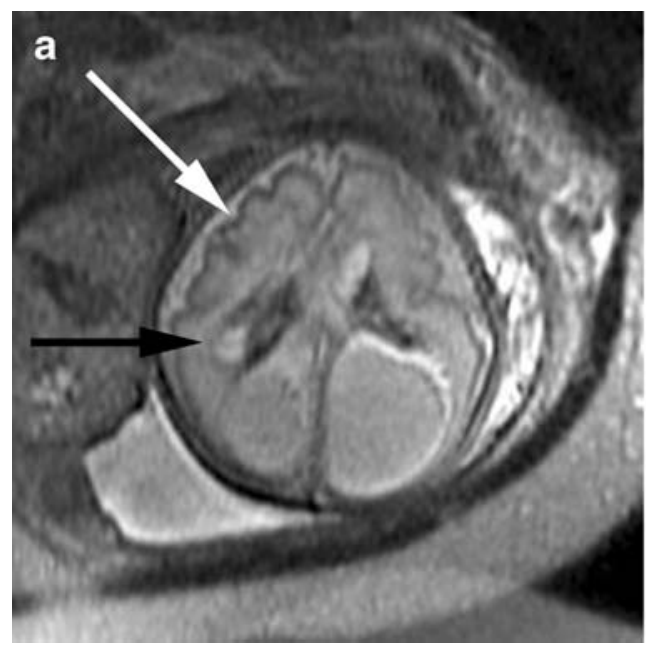

Fig. 4 Cortical malformation and hemorrhage in a 27 gestational week fetus. a Axial SSFSE T2-W image demonstrates abnormal cortical infoldings of the frontal lobes, consistent with polymicrogyria (white arrow). Areas of cystic encephalomalacia with hemorrhage are also seen in the developing white matter (black arrow). b Intraven-

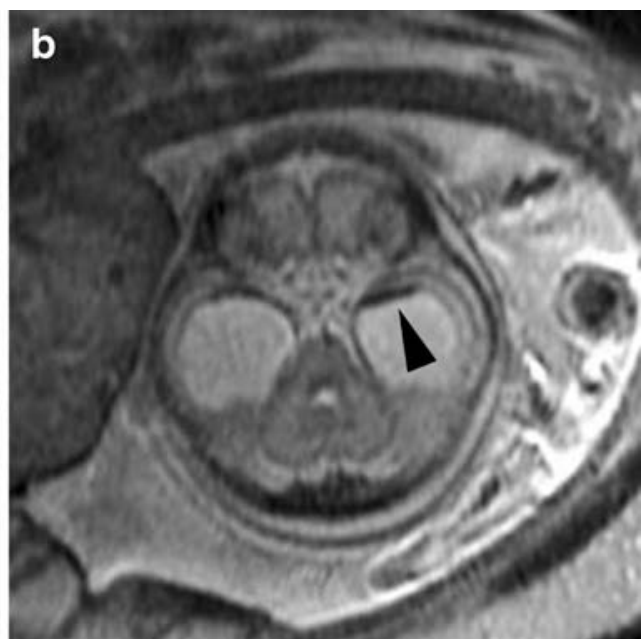

tricular hemorrhage is seen layering in the temporal horns bilaterally (arrowhead). The patient was referred for ventriculomegaly and choroid plexus cysts detected on prenatal sonogram. (Reprinted with permission [2]) 
Fig. 5 Absent corpus callosum in a 26 gestational week fetus referred for sonographically isolated mild ventriculomegaly. a Axial SSFSE T2-W image demonstrates dilatation of the posterior lateral ventricles (arrows). b Sagittal image demonstrates absent corpus callosum (compare with Fig. 8, where a normal corpus callosum is present)
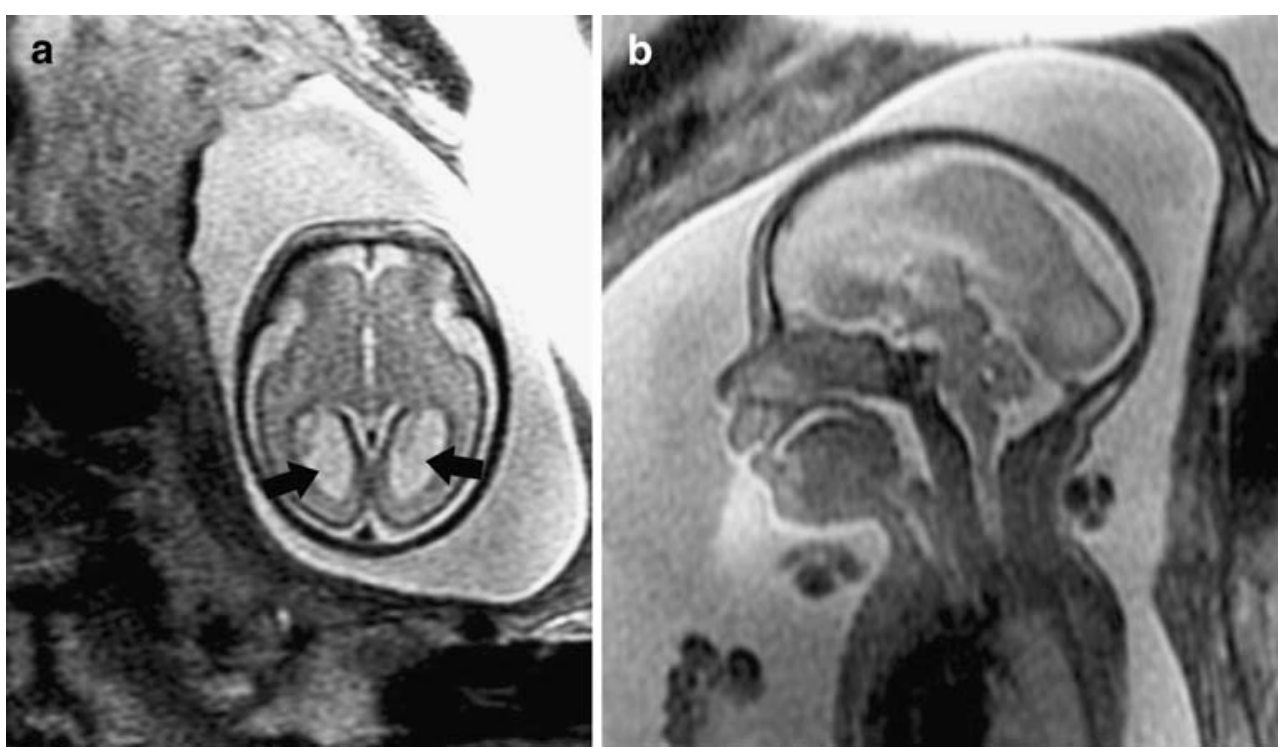

is important to realize that the corpus callosum can be severely stretched in cases of severe ventriculomegaly and thus it can be difficult to reliably identify the callosum even by fetal MRI. In such cases, identifying indirect signs of callosal agenesis (see below) might be helpful in determining whether the callosum cannot be visualized because it did not form or because it is severely thinned.

Fetal MRI can also detect cortical malformations, which can be seen in association with ventriculomegaly. These include but are not limited to lissencephaly, schizencephaly, and polymicrogyria. Lissencephaly appears as a smooth brain with an abnormally thickened multilayered pattern and absence of the expected sulci for the fetus' gestational

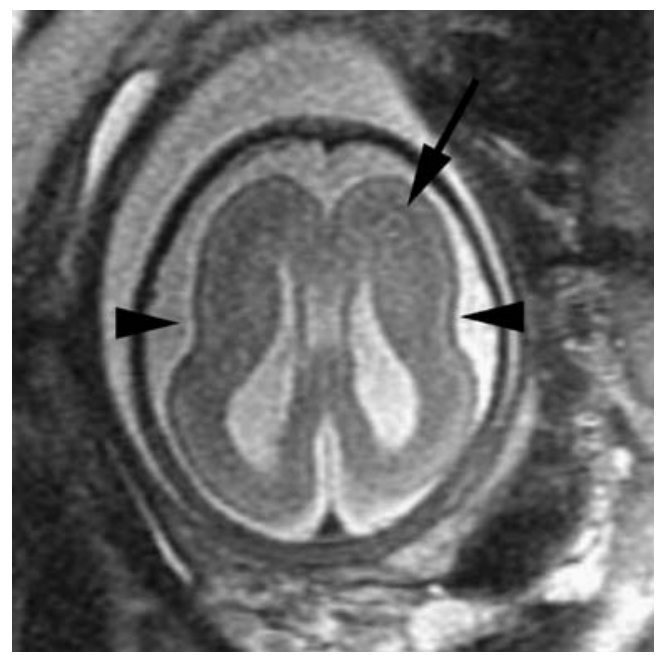

Fig. 6 Axial SSFSE T2-W image in a 34 gestational week fetus demonstrates abnormally shallow sylvian fissures (arrowheads) with absence of other sulci. A thick band of low signal intensity (arrow) is seen in the developing white matter, consistent with arrested migration of neurons. Findings are compatible with classical lissencephaly. (Reprinted with permission [119]) age (Fig. 6). Schizencephaly appears as a defect in the parenchyma, extending from the ventricular margin to the brain surface, which is lined by tissue that is isointense to the developing cortex; the ventricle is often dimpled at the location of the schizencephaly, and the adjacent cortex usually is affected by polymicrogyria (Fig. 7). Polymicrogyria appears as multiple abnormal infoldings of the developing cortex (see Fig. 4) and can be focal or diffuse. When polymicrogyria is identified, ischemic causes as well as genetic causes, including metabolic disturbances, and infectious causes should be considered. Although the sensitivity of fetal MRI for detecting malformations of cortical development is not known, it likely depends on the

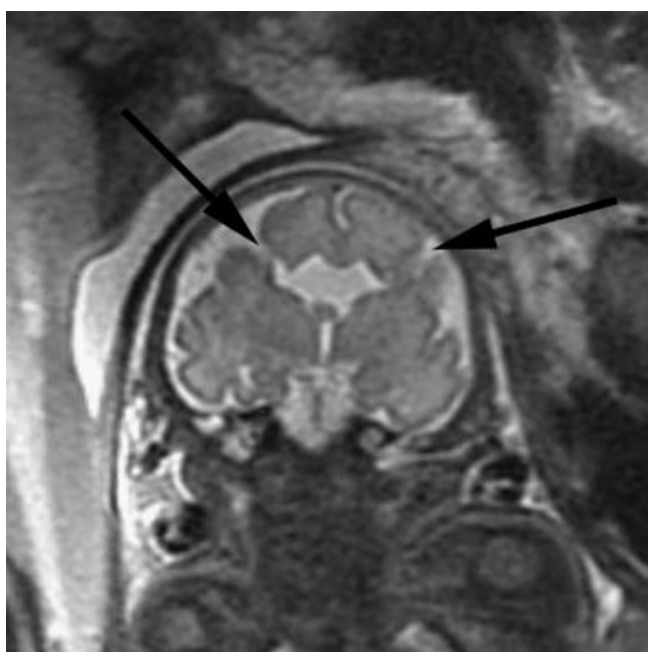

Fig. 7 Coronal SSFSE T2WI in a 33 gestational week fetus demonstrates bilateral clefts extending from the ventricle to the subarachnoid space, consistent with open lip schizencephalic defects (arrows). The adjacent sulcal pattern is abnormal, consistent with polymicrogyria. The cavum septum pellucidum is absent. (Reprinted with permission [119]) 
gestational age at the time of imaging as well as on the severity of the malformation, and repeat imaging at a later gestational age might be helpful.

\section{Abnormalities of the corpus callosum}

Fetal MR is useful in the evaluation of sonographically suspected callosal anomalies because the corpus callosum can be directly visualized in the sagittal and coronal planes as a curvilinear T2 hypointense structure located at the superior margin of the lateral ventricles, superior to the fornices (Fig. 8). Direct visualization of the callosum by sonography, however, is more difficult and thus sonography typically relies on indirect signs of callosal development (such as absence of the cavum septi pellucidi, dilated ventricular atria and occipital horns, and inferior orientation of the medial hemispheric sulci) to identify abnormalities of callosal formation. These indirect signs can also be seen with fetal MRI. On fetal MR, the corpus callosum is best assessed using thin $(3 \mathrm{~mm})$ midline sagittal images. Its length can be measured on midline sagittal images, and measurements can be compared with published normative data $[1,13,44]$, especially in cases of suspected callosal hypogenesis.

Fetal MR has been reported to have a greater detection of callosal agenesis as compared with prenatal US [45]. In addition, fetal MR can identify an intact corpus callosum in approximately $20 \%$ of cases referred for sonographically suspected callosal agenesis or hypogenesis, which has significant implications for patient counseling [46]. Additional callosal abnormalities, including hypogenesis (or partial agenesis), dysgenesis, and hypoplasia, can also be diagnosed by fetal MRI. Because of the normally thin

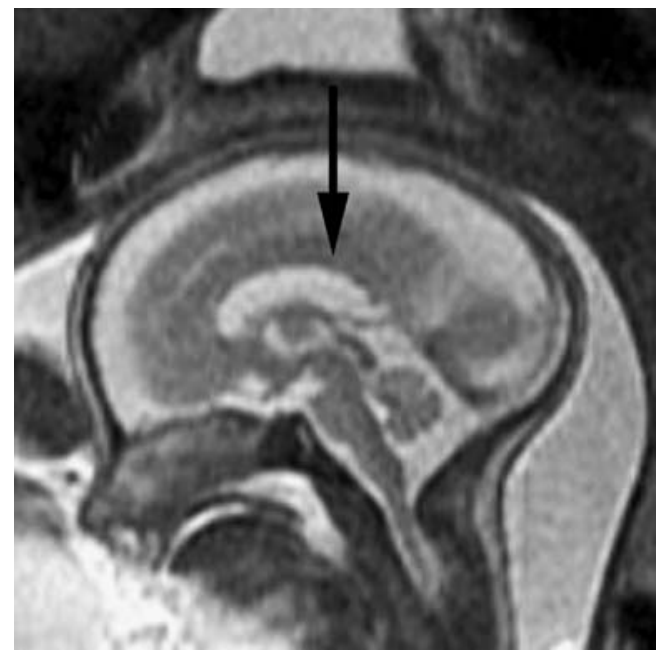

Fig. 8 Midline sagittal SSFSE T2-W image demonstrates the normal appearance of the corpus callosum (arrow). Obtaining a 3-mm nonoblique midline sagittal image is important when evaluating the corpus callosum. (Reprinted with permission [119]) appearance of the fetal corpus callosum, callosal hypoplasia is more difficult to diagnose, especially during the second trimester.

Fetal MRI is important in detecting additional abnormalities in cases of callosal agenesis. Indeed, detection of associated brain anomalies by fetal MR is greater than by prenatal sonography in these cases [45-49]; and additional anomalies are detected by fetal MR in up to $93 \%$ of cases [46, 49-51]. In nearly $20 \%$ of cases, the identification of additional findings by fetal MRI may suggest a specific disorder or syndrome associated with callosal agenesis; this has implications both for the current pregnancy as well as for the recurrence risk in future pregnancies [51]. In a recent report of 29 cases of callosal agenesis diagnosed by fetal MRI, abnormal sulcation was identified in nearly all fetuses, characterized by either too numerous cortical infoldings and/or delayed sulcation [51] (Fig. 9). Posterior fossa abnormalities were identified in one-third to one-half of cases and most commonly included a small and/or dysmorphic cerebellum, followed by small/absent vermis, and dysmorphic or small brainstem [51] (Fig. 10). Additional, less frequent abnormalities detected by fetal MRI include periventricular nodular heterotopia, dysplastic ventricles, abnormal deep gray nuclei, and parenchymal hemorrhage and/or injury [51]. Interestingly, additional abnormalities such as abnormal sulcal morphology and infratentorial abnormalities were present in those with poor neurodevelopmental outcome. Thus, when fetal MRI is performed for cases of suspected callosal agenesis, the supratentorial structures as well as the infratentorial structures should be carefully examined.

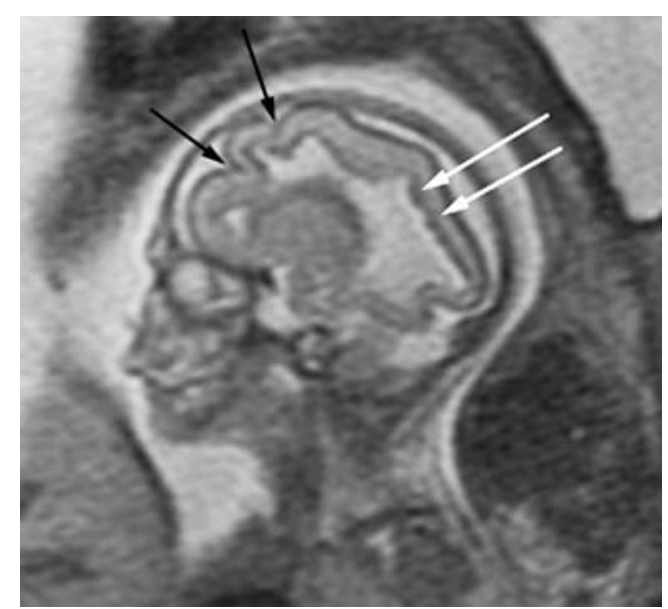

Fig. 9 Sagittal SSFSE T2-W image in a 22 gestational week fetus demonstrates multiple abnormal infoldings of the cortex (black arrows). The lateral ventricle has an abnormal shape with multiple undulations along its margin and periventricular nodular heterotopia (white arrows). The multilayered pattern of the supratentorial parenchyma is absent. A diagnosis of Aicardi syndrome was confirmed postnatally. (Reprinted with permission [51]) 
Fig. 10 Multiple abnormalities in a 36 gestational week fetus. a Coronal SSFSE T2-W image shows a small left cerebellar hemisphere (arrow). The sulcation pattern of both cerebral hemispheres is diffusely abnormal, with too many infoldings of the cortex. b Sagittal image demonstrates callosal agenesis, small pons (white arrow), small vermis (black arrow), and mega cisterna magna. (Reprinted with permission [51])
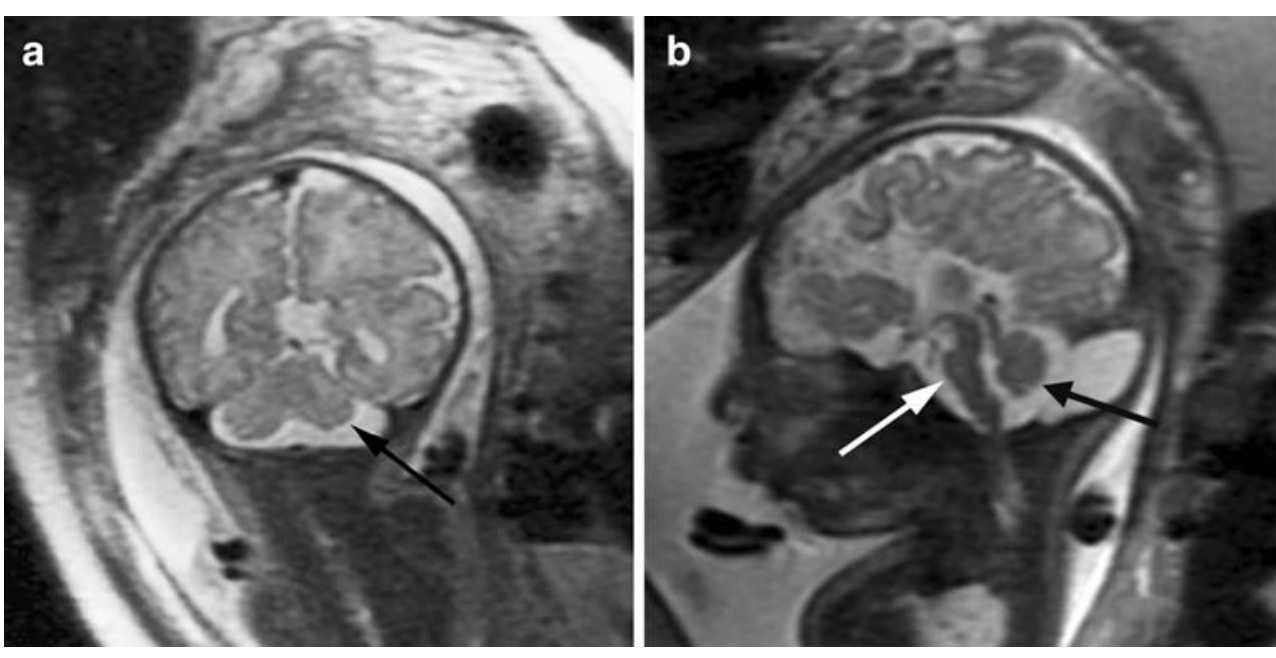

Posterior fossa abnormalities

Fetal MRI is helpful in evaluating abnormalities of the posterior fossa. It allows direct visualization of the cerebellar hemispheres, vermis, and brainstem in three orthogonal planes and thus allows better assessment of their morphology. Normative measurements of the cerebellum, vermis, and brainstem on fetal MRI are available for different gestational ages $[1,13,44,52,53]$. Posterior fossa abnormalities evaluated by fetal MRI include DandyWalker continuum, cerebellar hypoplasia, cerebellar dysplasia, cerebellar hemorrhage, and Chiari II malformation [23, 45, 47, 48, 54-56]. Because many posterior fossa abnormalities are associated with supratentorial abnormalities, fetal MRI is also used to evaluate the supratentorial brain when an infratentorial abnormality is identified. Although fetal MRI can provide additional information about suspected posterior fossa anomalies, it is important to be aware of its limitations, particularly when performed early in gestation [57].

In cases of sonographically suspected vermian abnormalities, fetal MRI can assess the size and morphology of the vermis (Fig. 11), or confirm its absence. The vermis should be evaluated not just on 3-mm midline sagittal images but also on axial and coronal images, because partial volume averaging through the medial aspect of the cerebellar hemispheres can falsely appear as an abnormal vermis on midline sagittal image or falsely mimic a vermis in cases of rhombencephalosynapsis. The vermis is more difficult to accurately assess at younger gestational ages (such as 20 weeks to 21 weeks) at least in part because of fetal motion and the difficulty obtaining true midline sagittal images, and imaging at a later gestational age is preferable when possible. A recent study demonstrated that one-third of patients with inferior vermian hypoplasia diagnosed by fetal MRI had a normal-size vermis on postnatal MRI [58]. Thus, when isolated inferior vermian hypoplasia is identified by fetal MRI, a follow-up MRI is recommended.

The cerebellar hemispheres can also be directly visualized in multiple planes, and their morphology and signal intensity should be examined in suspected posterior fossa abnormalities (Fig. 12). The diameter of the cerebellar hemispheres has been measured by fetal MRI and increases during gestation $[1,13,44,52,53]$. Changes in the cerebellum during development are also apparent on fetal diffusion-weighted imaging and are characterized by a progressive decline in mean diffusivity with increasing gestational age $[59,60]$.

Normative measurements of the pons on fetal MRI have been published [1,44], and the pons should be measured in cases of suspected cerebellar or supratentorial abnormalities. The brainstem can also be examined for focal or diffuse morphologic or signal abnormalities (Fig. 10). The

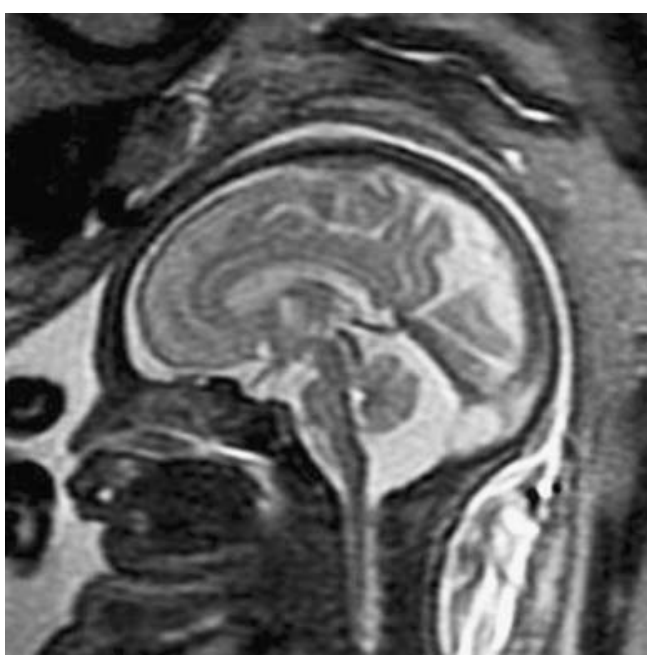

Fig. 11 Sagittal SSFSE T2-W image in a 33 gestational week fetus demonstrates a large cisterna magna with a normal-appearing vermis, excluding the diagnosis of a Dandy-Walker malformation. (Reprinted with permission [119]) 
Fig. 12 Dysmorphic cerebellum in a 29 gestational week fetus. a Sagittal SSFSE T2-W image demonstrates mild upward rotation of the vermis, which is slightly small inferiorly. b Coronal SSFSE T2-W image demonstrates small left cerebellum (arrow). (Reprinted with permission [119])
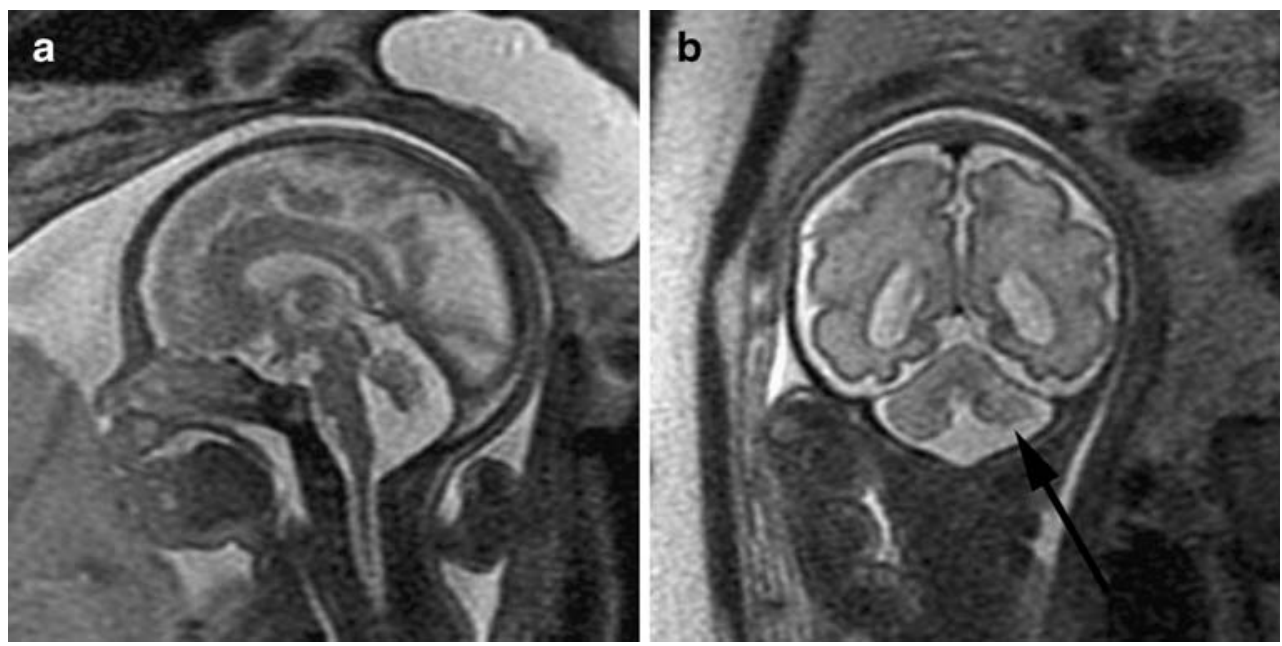

dorsal pons and medulla normally appear hypointense on $\mathrm{T} 2-\mathrm{W}$ images and hyperintense on T1-weighted images relative to the ventral brainstem as early as $23-25$ gestational weeks $[53,56,61]$. The dorsal midbrain appears hypointense on $\mathrm{T} 2$ and hyperintense on $\mathrm{T} 1$ later in gestation, by about 31-32 weeks [61, 62]. Diffusionweighed imaging can be used to evaluate the brainstem, as there is a normal decline in mean diffusivity in the pons with increasing gestational age $[59,60]$.

In cases of Chiari II malformation, fetal MRI is used to characterize the severity of the hindbrain herniation, as well as the ventricular size and morphology, with ventricles often appearing angular in their morphology [63] (Fig. 13). Additional developmental brain abnormalities are frequently seen in children with Chiari II malformations and these can be detected using fetal MRI. In particular, $57 \%$ of children with Chiari II malformations have abnormalities of the corpus callosum, most commonly hypoplasia and dysplasia [64], and fetal MRI allows direct visualization of callosal abnormalities (Fig. 14). In addition to callosal abnormalities, periventricular nodular heterotopia, microgyria, polymicrogyria, cerebellar dysplasia, syringohydromyelia, and diastematomyelia are seen in association with Chiari II malformations [64-66]. Rarely, destructive lesions can be detected in fetuses with Chiari II malformations, such as germinal matrix hemorrhage. Following in utero repair of the myelomeningocele, improvement of hindbrain herniation can be observed on fetal MRI [67].

Fetal MRI is also helpful in evaluating echogenic posterior fossa masses. Fetal MRI can be used to identify the location of the mass (intraaxial vs. extraaxial), and to assess the integrity of the cerebellar hemispheres, vermis,

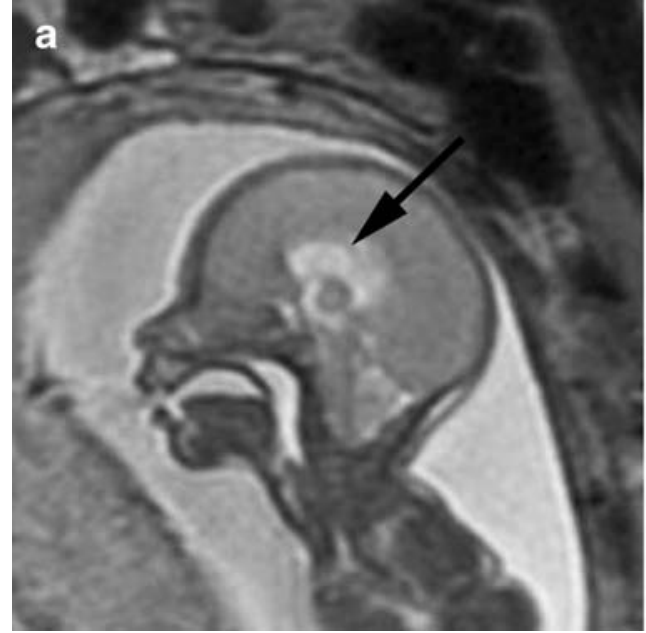

Fig. 13 Chiari II malformation in a 22 gestational week fetus. a Sagittal SSFSE T2WI in a demonstrates a small posterior fossa with inferior displacement of the cerebellum, consistent with a Chiari II malformation. The corpus callosum is hypogenetic (arrow). There is diffuse effacement of the subarachnoid spaces, which is typically

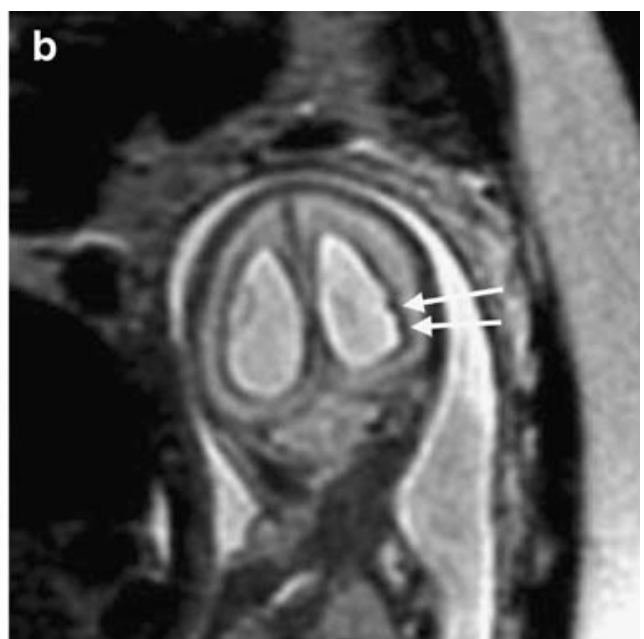

observed in Chiari II malformation. b Coronal SSFSE T2-W image in the same fetus demonstrates bilateral ventriculomegaly as well as two small hypointense nodules along the lateral margin of the atrium of the left lateral ventricle, consistent with periventricular nodular heterotopia (arrows). (Reprinted with permission [119]) 
Fig. 14 Dural sinus malformation with thrombosis in a 24 gestational week fetus. a Axial SSFSE T2-W image demonstrates a large intradural mass that is a slightly $\mathrm{T} 2$ hypointense (arrows). Findings are compatible with a dural sinus malformation. b Coronal SSFSE T2-W image demonstrates a focal ovoid area of T2 hypointensity within the dural sinus malformation, consistent with focal thrombus (arrow). (Reprinted with permission [119])
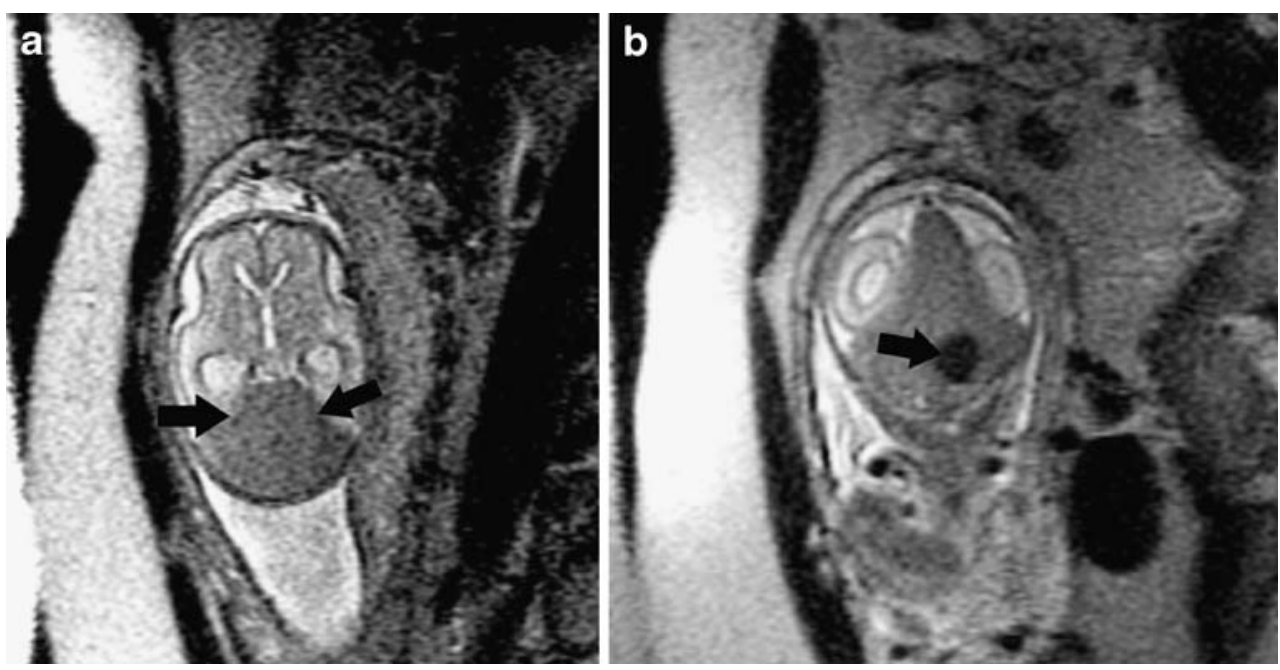

and brainstem. In these cases, gradient echo T2*-weighted imaging might be helpful to look for associated blood products. Both extraaxial posterior fossa hemorrhages and intraparenchymal cerebellar hemorrhages can be related to maternal/fetal trauma [68] and to vascular malformations [69, 70]. Dural sinus malformations often appear as slightly T2 hypointense and $\mathrm{T} 1$ isointense mass-like lesions involving the torcula; thrombus within the dural venous sac appears as T1 hyperintensity and marked T2 hypointensity and can be associated with a favorable outcome [71] (Fig. 14). Vascular causes of intraparenchymal cerebellar hemorrhage include germinal matrix hemorrhages and underlying vascular malformations such as cavernous malformations [56]. Although uncommon, cerebellar hemorrhage has also been reported in cases of infection with cytomegalovirus [72, 73] and in both immune and nonimmune hydrops fetalis [74, 75], presumably from associated hematological and hemodynamic abnormalities. When a cerebellar hemorrhage is identified, infection should be considered, and a careful search for other abnormalities (e.g., intrauterine growth retardation, microcephaly, calcifications, echogenic bowel, and hydrops fetalis) should be initiated.

\section{Complications of monochorionic twin pregnancies}

Although most fetal MRI is performed for evaluation of a sonographically suspected abnormality, fetal MRI is increasingly being performed in cases where sonography of the fetal brain is normal but the fetus is at a known increased risk for neurodevelopmental abnormalities. This occurs in complications of monochorionic twin pregnancy, such as co-twin demise and twin-twin transfusion syndrome. Monochorionic twins share a common placenta that often contains abnormal intertwin vascular connections. Because of the placental vascular anatomy, the overall morbidity and mortality of monochorionic twins is much higher than that of diamniotic twins [76-78].
In utero death of a co-twin is associated with an increased risk of neurologic impairment in the surviving co-twin, most likely a result of acute cerebral hypoperfusion at the time of demise, or possibly thromboemboli [79]. Fetal MR can identify destructive parenchymal lesions that might not be detected by prenatal sonography, such as those that are seen in the surviving co-twin following co-twin demise [21, 45, 47, 80-82]. Ischemic injuries can appear as focal or diffuse areas of increased signal on T2-W images in the germinal matrix, developing white matter, and/or cortex (Fig. 15). Ischemic injury to the fetal brain can also result in cortical malformations such as polymicrogyria, which can be detected by fetal MR (Fig. 16) [80]. In a recent study of survivors of spontaneous monochorionic co-twin demise, fetal MRI detected sonographically occult abnormalities in one-third of patients, including

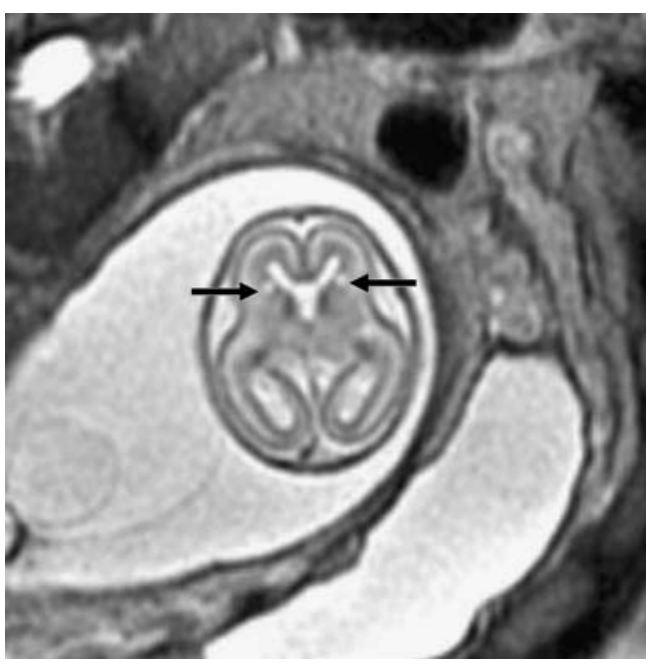

Fig. 15 Axial SSFSE T2-W image in a 20 gestational week fetus demonstrates bilateral germinolytic cysts (arrows) consistent with prior germinal matrix injury. A portion of the demised twin is seen in the lower part of the image. Findings were confirmed on coronal image (not shown). (Reprinted with permission [81]) 
Fig. 16 Encephalomalacia and malformation of cortical development in a 23 gestational week fetus. a Coronal SSFSE T2 image demonstrates encephalomalacia of the left frontal and parietal lobes (arrow). The demised twin is also seen (arrowhead). b Abnormal infoldings of the developing cortex are consistent with polymicrogyria (arrow). (Reprinted with permission [119])
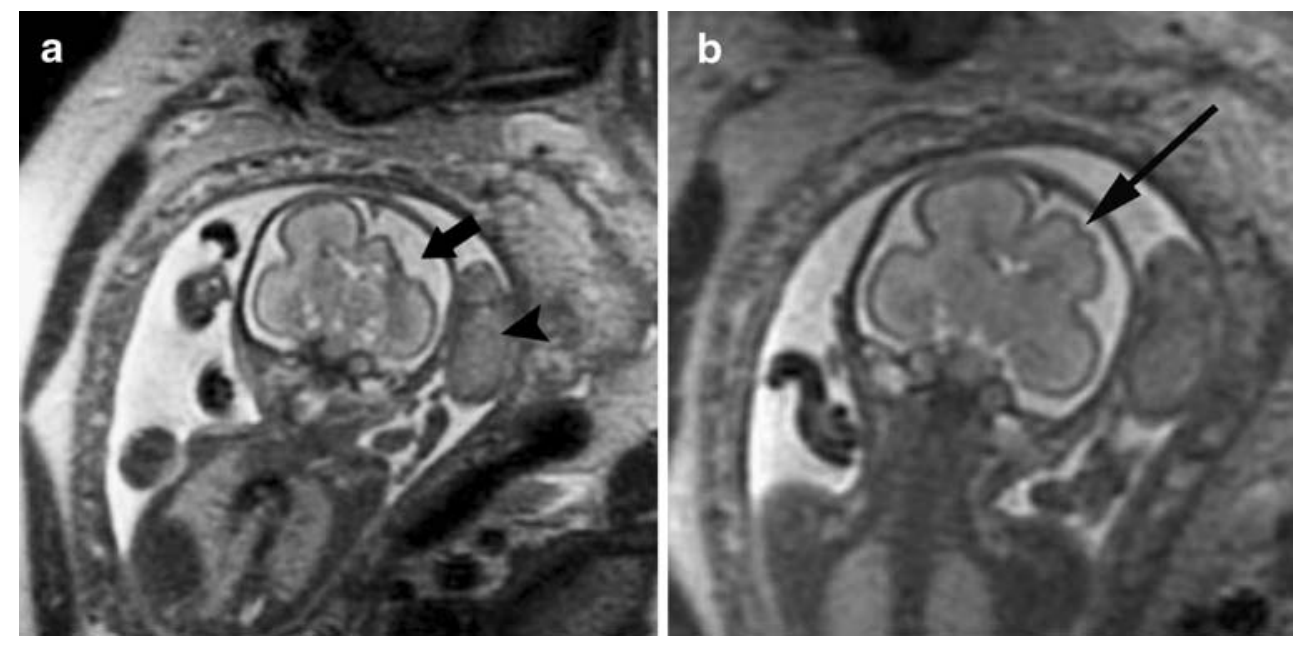

polymicrogyria, encephalomalacia, germinolytic cysts, hemorrhage, ventriculomegaly, and delayed sulcation [81]. Diffusion-weighted imaging can detect more acute injury in the surviving co-twin immediately following cotwin demise [83, 84]. In cases of co-twin demise, fetal MRI (including DWI) should be performed as early as possible to identify acute injury, and then repeated at least 2 weeks after the suspected demise to detect subacute/ chronic sequelae of intracranial injury in the surviving fetus.

Another serious complication of monochorionic twinning is twin-twin transfusion syndrome. Twin-twin transfusion syndrome is characterized by abnormal blood flow from the smaller, donor twin to the larger, recipient twin via placental vascular connections. The recipient twin develops polyhydramnios because of volume overload, and the donor twin develops oligohydramnios resulting in a "stuck twin." The exact pathophysiology underlying twin-twin transfusion syndrome is complex; however, it appears to be related to an imbalance of intertwin arteriovenous connections [85]. The morbidity rate is very high in twin-twin transfusion syndrome, and both the recipient and the donor twin are at risk for cerebral ischemia and hemorrhage [81, 86-93]. Fetal MR can be used to identify brain injury in twins affected by twin-twin transfusion syndrome, although imaging the polyhydramniotic twin is difficult because of excessive fetal motion. Brain abnormalities detected by fetal MRI are similar to those seen in survivors of co-twin demise and include encephalomalacia, periventricular white matter injury, germinal matrix hemorrhages, intraventricular hemorrhage, intraparenchymal hemorrhage, and cortical malformation [81, 83, 88, 91, 94, 95]. Laser ablation of the intervascular connections can be performed in cases of twin-twin transfusion syndrome. In such cases, fetal MR is often used to evaluate the brain both before and following surgical intervention.

\section{Research applications}

Although clinically used to evaluate fetuses with either detected brain abnormalities or increased risk for brain abnormalities, fetal MRI is also used to study normal in utero brain development. This is important for establishing normative measures that can be used to better identify cases of abnormal brain development. Using fetal DWI, normative mean diffusivity values during the second and third trimesters have been established [5, 59, $60,96]$. These studies demonstrate that in utero cerebral maturation is characterized by a progressive decline in mean diffusivity in most areas of the fetal brain $[5,59,60$, 96]. Interestingly, the absolute mean diffusivity values, as well as the rates of decline in mean diffusivity with increasing gestational age, vary in different areas of the fetal brain. In particular, mean diffusivity values are higher in the developing white matter as compared to the deep gray nuclei $[5,60]$. Moreover, mean diffusivity values decline most rapidly in the cerebellum and thalamus with increasing gestational age [59, 60]. The regional differences in mean diffusivity during gestation likely reflect differences in brain development because of many factors, including increasing cellularity, neuronal maturation, and myelination. Indeed, areas that are known to mature and myelinate earlier have lower mean diffusivity compared to areas that mature later. Thus DWI provides a quantitative marker of in utero brain development. Moreover, diffusion tensor imaging (DTI) has been recently been applied in vivo [97], although it is more limited by fetal motion. Certain fiber tracts, such as the sensorimotor tracts and the corpus callosum, can be depicted in fetuses during the second and third trimesters [97]. Post-processing methods have also recently resulted in the development of 3D high-resolution diffusion tensor images of the fetal brain [98]. Future studies using DWI 
and DTI to characterize and identify abnormalities of fetal brain development are needed.

Because of the long acquisition time (several minutes) and size of the voxel relative to the fetal brain size, MR spectroscopy is limited to application in the third trimester when the fetal head is relatively large and engaged in the pelvis. Normal metabolites such as $\mathrm{N}$-acetyl aspartate, creatine, choline, and myo-inositol can be detected, and several studies have shown changes in metabolite levels during gestation [7, 99-102].

Functional MR studies have also recently been performed in fetuses during the third trimester and have primarily involved the application of an auditory stimulus to the maternal abdomen [103-106]. These studies have shown temporal lobe activation in response to an auditory stimulus in some fetuses, as early as 33 gestational weeks. A functional MRI study using visual stimulation to the maternal abdomen has also been published [107]. The application of functional MRI in utero, however, is limited by susceptibility artefacts from maternal organs and by fetal motion, requiring either complicated correction algorithms of fetal motion or the administration of maternal sedation (which is not routinely performed in the United States) [103-106].

An MR technique that has been described recently allows the noninvasive measurement of the oxygen partial pressure of fluids. This has been applied to the fetal cerebrospinal fluid [108]. Because the oxygen content of cerebrospinal fluid can give information about the oxygenation of the surrounding cerebral tissues, this method might offer insight into conditions that result in decreased fetal cerebral oxygenation [108].

Significant advances in both fetal MRI post-processing and structural analysis methods promise to provide new quantitative biomarkers of early brain development and improve our understanding of in utero brain growth. Because the motion of an unsedated fetus within the deforming tissues of the mother precludes the acquisition of conventional 3-D images that are typically acquired in sedated children, methods have been developed for retrospective motion correction of ultrafast multi-slice fetal data $[109,110]$. These methods allow the formation of a single geometrically consistent 3-D image from conventional clinical ultrafast $\mathrm{T} 2$ weighted images of a moving fetus by aligning corresponding rigid anatomy of the fetal head in different slices, while discarding matches of the surrounding deforming tissues of the mother. These allow, for the first time, the study of normal in utero brain development at high-resolution and in three dimensions [109-112]. Moreover, post-processing methods have also recently resulted in the development of 3-D highresolution diffusion tensor images of the fetal brain [98].

The developing anatomy of the fetal brain cannot be directly analyzed using methods developed for adult brain studies, and the recent availability of routine 3-D brain image data from fetuses has motivated the development of approaches to the analysis of early developing tissues. These include specific methods to automatically identify and label transient tissue structures such as the germinal matrix within MRI data using computational atlases that capture the developing laminar structure of the brain over time [113-115]. Such automated tissue segmentation steps allow the morphometric analysis of the developing fetal brain using techniques that quantify tissue volume, surface folding and cortical thickness [116-118]. These recent advances provide new measures by which normal brain development can be studied. Moreover, they can now be applied to fetuses with specific brain abnormalities, with the goal of being better able to understand and detect brain abnormalities that have their origins in utero.

\section{Conclusion}

Fetal MRI is being increasingly used to assess for fetal brain abnormalities. Although significant progress in the field of fetal MR imaging has occurred during the last two decades, continued technical and research advances will likely contribute to significant growth of the field. Because fetal MR involves many disciplines, the promise of fetal MR will be best achieved through continued multidisciplinary collaborative efforts.

Open Access This article is distributed under the terms of the Creative Commons Attribution Noncommercial License which permits any noncommercial use, distribution, and reproduction in any medium, provided the original author(s) and source are credited.

\section{References}

1. Garel C (2004) MRI of the fetal brain: normal development and cerebral pathologies. Springer, Berlin

2. Glenn OA, Barkovich AJ (2006) Magnetic resonance imaging of the fetal brain and spine: an increasingly important tool in prenatal diagnosis, part 1. AJNR 27:1604-1611

3. Prayer D, Kasprian G, Krampl E et al (2006) MRI of normal fetal brain development. Eur J Radiol 57:199-216

4. Glenn OA (2009) Normal development of the fetal brain by MRI. Semin Perinatol 33:208-219

5. Righini A, Bianchini E, Parazzini C et al (2003) Apparent diffusion coefficient determination in normal fetal brain: a prenatal MR imaging study. AJNR 24:799-804

6. Prayer D, Brugger P, Mittermayer C et al (2003) Diffusionweighted imaging in intrauterine fetal brain development. In: Abstracts of the American Society of Neuroradiology meeting, Washington

7. Kok RD, van den Berg PP, van den Bergh AJ et al (2002) Maturation of the human fetal brain as observed by $1 \mathrm{H}$ MR spectroscopy. Magn Reson Med 48:611-616 
8. McKenzie CA, Levine D, Morrin M et al (2004) ASSET enhanced SSFSE imaging of the fetus. In: Abstracts of the International Society for Magnetic Resonance in Medicine meeting, Kyoto

9. Busse R, Carrillo A, Brittain J et al (2002) On-demand real-time imaging: interactive multislice acquisition applied to prostate and fetal imaging. In: Abstracts of the International Society for Magnetic Resonance in Medicine meeting, Honolulu

10. Levine D, Cavazos C, Kazan-Tannus JF et al (2006) Evaluation of real-time single-shot fast spin-echo MRI for visualization of the fetal midline corpus callosum and secondary palate. AJR 187:1505-1511

11. Cardoza JD, Goldstein RB, Filly RA (1988) Exclusion of fetal ventriculomegaly with a single measurement: the width of the lateral ventricular atrium. Radiology 169:711-714

12. Levine D, Trop I, Mehta TS et al (2002) MR imaging appearance of fetal cerebral ventricular morphology. Radiology 223:652-660

13. Parazzini C, Righini A, Rustico M et al (2008) Prenatal magnetic resonance imaging: brain normal linear biometric values below 24 gestational weeks. Neuroradiology 50:877-883

14. Twickler DM, Reichel T, McIntire DD et al (2002) Fetal central nervous system ventricle and cisterna magna measurements by magnetic resonance imaging. Am J Obstet Gynecol 187:927-931

15. Garel C, Alberti C (2006) Coronal measurement of the fetal lateral ventricles: comparison between ultrasonography and magnetic resonance imaging. Ultrasound Obstet Gynecol 27: 23-27

16. Wagenvoort AM, Bekker MN, Go AT et al (2000) Ultrafast scan magnetic resonance in prenatal diagnosis. Fetal Diagn Ther $15: 364-372$

17. Levine D, Barnes PD, Madsen JR et al (1999) Central nervous system abnormalities assessed with prenatal magnetic resonance imaging. Obstet Gynecol 94:1011-1019

18. Morris JE, Rickard S, Paley MN et al (2007) The value of inutero magnetic resonance imaging in ultrasound diagnosed foetal isolated cerebral ventriculomegaly. Clin Radiol 62:140-144

19. Salomon LJ, Ouahba J, Delezoide AL et al (2006) Thirdtrimester fetal MRI in isolated 10- to $12-\mathrm{mm}$ ventriculomegaly: is it worth it? BJOG 113:942-947

20. Simon EM, Goldstein RB, Coakley FV et al (2000) Fast MR imaging of fetal CNS anomalies in utero. AJNR 21:1688-1698

21. de Laveaucoupet J, Audibert F, Guis F et al (2001) Fetal magnetic resonance imaging (MRI) of ischemic brain injury. Prenat Diagn 21:729-736

22. Coakley FV, Hricak H, Filly RA et al (1999) Complex fetal disorders: effect of MR imaging on management - preliminary clinical experience. Radiology 213:691-696

23. D'Ercole CD, Girard N, Boubli L et al (1993) Prenatal diagnosis of fetal cerebral abnormalities by ultrasonography and magnetic resonance imaging. Eur J Obstet Gynecol Reprod Biol 50:177184

24. Agid R, Lieberman S, Nadjari M (2006) Prenatal MR diffusionweighted imaging in a fetus with hemimegalencephaly. Pediatr Radiol 36:138-140

25. Arora A, Bannister CM, Russell S et al (1998) Outcome and clinical course of prenatally diagnosed cerebral ventriculomegaly. Eur J Pediatr Surg 8:198-199

26. Bromley B, Frigoletto FD, Benacerraf BR (1991) Mild fetal lateral cerebral ventriculomegaly: clinical course and outcome. Am J Obstet Gynecol 164:863-867

27. Chervenak FA, Duncan C, Ment LR et al (1984) Outcome of fetal ventriculomegaly. Lancet 2:179-181

28. Gupta JK, Bryce FC, Lilford RJ (1994) Management of apparently isolated fetal ventriculomegaly. Obstet Gynecol Surv 49:716-721
29. Goldstein RB, La Pidus AS, Filly RA et al (1990) Mild lateral cerebral ventricular dilatation in utero: clinical significance and prognosis. Radiology 176:237-242

30. Nyberg DA, Mack LA, Hirsch J et al (1987) Fetal hydrocephalus: sonographic detection and clinical significance of associated anomalies. Radiology 163:187-191

31. Vergani P, Locatelli A, Strobelt N et al (1998) Clinical outcome of mild fetal ventriculomegaly. Am J Obstet Gynecol 178:218 222

32. Mahony BS, Nyberg DA, Hirsch JH et al (1988) Mild idiopathic lateral cerebral ventricular dilatation in utero: sonographic evaluation. Radiology 169:715-721

33. Drugan A, Krause B, Canady A et al (1989) The natural history of prenatally diagnosed cerebral ventriculomegaly. JAMA 261:1785-1788

34. Nicolaides KH, Berry S, Snijders RJM et al (1990) Fetal lateral cerebral ventriculomegaly: associated malformations and chromosomal defects. Fetal Diagn Ther 5:5-14

35. Greco P, Laforgia N, Vimercati A et al (2001) Mild ventriculomegaly as a counselling challenge. Fetal Diagn Ther 16:398-401

36. Patel MD, Filly RA, Hersch DR et al (1994) Isolated mild fetal cerebral ventriculomegaly: clinical course and outcome. Radiology 192:759-764

37. Pilu G, Falco P, Gabrielli S et al (1999) The clinical significance of fetal isolated cerebral borderline ventriculomegaly: report of 31 cases and review of the literature. Ultrasound Obstet Gynecol $14: 320-326$

38. Bloom SL, Bloom DD, Dellanebbia C et al (1997) The developmental outcome of children with antenatal mild isolated ventriculomegaly. Obstet Gynecol 90:93-97

39. Mercier A, Eurin D, Mercier PY et al (2001) Isolated mild fetal cerebral ventriculomegaly: a retrospective analysis of 26 cases. Prenat Diagn 21:589-595

40. Gaglioti P, Danelon D, Bontempo S et al (2005) Fetal cerebral ventriculomegaly: outcome in 176 cases. Ultrasound Obstet Gynecol 25:372-377

41. Breeze A, Dey P, Lees C et al (2005) Obstetric and neonatal outcomes in apparently isolated mild fetal ventriculomegaly. J Perinat Med 33:236-240

42. Falip C, Blanc N, Maes E et al (2007) Postnatal clinical and imaging follow-up of infants with prenatal isolated mild ventriculomegaly: a series of 101 cases. Pediatr Radiol 37:981989

43. Callen PW, Callen AL, Glenn OA et al (2008) Columns of the fornix, not to be mistaken for the cavum septi pellucidi on prenatal sonography. J Ultrasound Med 27:25-31

44. Tilea B, Alberti C, Adamsbaum C et al (2009) Cerebral biometry in fetal magnetic resonance imaging: new reference data. Ultrasound Obstet Gynecol 33:173-181

45. Sonigo PC, Rypens FF, Carteret M et al (1998) MR imaging of fetal cerebral anomalies. Pediatr Radiol 28:212-222

46. Glenn O, Goldstein R, Li K et al (2005) Fetal MRI in the evaluation of fetuses referred for sonographically suspected abnormalities of the corpus callosum. J Ultrasound Med 24:791-804

47. Garel C, Brisse H, Sebag G et al (1998) Magnetic resonance imaging of the fetus. Pediatr Radiol 28:201-211

48. Levine D, Barnes PD, Madsen JR et al (1997) Fetal central nervous system anomalies: MR imaging augments sonographic diagnosis. Radiology 204:635-642

49. d'Ercole C, Girard N, Cravello L et al (1998) Prenatal diagnosis of fetal corpus callosum agenesis by ultrasonography and magnetic resonance imaging. Prenat Diagn 18:247-253

50. Rapp B, Perrotin F, Marret H et al (2002) Interet de l'IRM cerebrale foetale pour le diagnostic et le pronostic prenatal des agenesies du corps calleux. J de Gynecologie Obstetrique et 
Biologie de la Reproduction. J Gynecol Obstet Biol Reprod (Paris) 31:173-182

51. Tang PH, Bartha AI, Norton ME et al (2009) Agenesis of the corpus callosum: an MR imaging analysis of associated abnormalities in the fetus. AJNR 30:257-263

52. Reichel T, Ramus RM, Caire JT et al (2003) Fetal central nervous system biometry on MR imaging. AJR 180:1155-1158

53. Triulzi F, Parazzini C, Righini A (2006) Magnetic resonance imaging of fetal cerebellar development. Cerebellum 5:199205

54. Kubik-Huch RA, Huisman TA, Wisser J et al (2000) Ultrafast MR imaging of the fetus. AJR 174:1599-1606

55. Dinh DH, Wright RM, Hanigan WC (1990) The use of magnetic resonance imaging for the diagnosis of fetal intracranial anomalies. Child's Nerv Syst 6:212-215

56. Adamsbaum C, Moutard ML, Andre C et al (2005) MRI of the fetal posterior fossa. Pediatr Neurol 35:124-140

57. Limperopoulos C, Robertson RL Jr, Khwaja OS et al (2008) How accurately does current fetal imaging identify posterior fossa anomalies? AJR 190:1637-1643

58. Limperopoulos C, Robertson RL, Estroff JA et al (2006) Diagnosis of inferior vermian hypoplasia by fetal magnetic resonance imaging: potential pitfalls and neurodevelopmental outcome. Am J Obstet Gynecol 194:1070-1076

59. Schneider JF, Confort-Gouny S, Le Fur Y et al (2007) Diffusionweighted imaging in normal fetal brain maturation. Eur Radiol 17:2422-2429

60. Schneider MM, Berman JI, Baumer FM et al (2009) Normative apparent diffusion coefficient values in the developing fetal brain. AJNR 30:1799-1803

61. Girard N, Raybaud C, Poncet M (1995) In vivo MR study of brain maturation in normal fetuses. AJNR 16:407-413

62. Stazzone MM, Hubbard AM, Bilaniuk LT et al (2000) Ultrafast MR imaging of the normal posterior fossa in fetuses. AJR 175:835-839

63. Levine D, Trop I, Mehta T et al (2002) MR imaging appearance of fetal cerebral ventricular morphology. Radiology 223:652-660

64. Miller E, Widjaja E, Blaser S et al (2008) The old and the new: supratentorial MR findings in Chiari II malformation. Child's Nerv Syst 24:563-575

65. Gilbert JN, Jones KL, Rorke LB et al (1986) Central nervous system anomalies associated with meningomyelocele, hydrocephalus and the Arnold-Chiari malformation: reappraisal of theories regarding the pathogenesis of posterior neural tube closure defects. Neurosurgery 18:559-564

66. Wolpert S, Anderson M, Scott R et al (1987) Chiari II malformation: MR imaging evaluation. AJR 149:1033-1042

67. Sutton LN, Adzick NS, Bilaniuk LT et al (1999) Improvement in hindbrain herniation demonstrated by serial fetal magnetic resonance imaging following fetal surgery for myelomeningocele. JAMA 282:1826-1831

68. Breysem L, Cossey V, Mussen E et al (2004) Fetal trauma: brain imaging in four neonates. Eur Radiol 14:1609-1614

69. Guibaud L, Garel C, Annie B et al (2003) Prenatal diagnosis of capillary telangiectasia of the cerebellum - ultrasound and MRI features. Prenat Diagn 23:791-796

70. Sharony R, Kidron D, Aviram R et al (1999) Prenatal diagnosis of fetal cerebellar lesions: a case report and review of the literature. Prenat Diagn 19:1077-1080

71. Merzoug V, Flunker S, Drissi C et al (2008) Dural sinus malformation (DSM) in fetuses. Diagnostic value of prenatal MRI and follow-up. Eur Radiol 18:692-699

72. Ortiz JU, Ostermayer E, Fischer T et al (2004) Severe fetal cytomegalovirus infection associated with cerebellar hemorrhage. Ultrasound Obstet Gynecol 23:402-406
73. Moinuddin A, McKinstry RC, Martin KA et al (2003) Intracranial hemorrhage progressing to porencephaly as a result of congenitally acquired cytomegalovirus infection - an illustrative report. Prenat Diagn 23:797-800

74. Glenn OA, Bianco K, Barkovich AJ et al (2007) Fetal cerebellar hemorrhage in parvovirus-associated nonimmune hydrops fetalis. J Matern Fetal Neonatal Med 20:769-772

75. Ghi T, Brondelli L, Simonazzi G et al (2004) Sonographic demonstration of brain injury in fetuses with severe red blood cell alloimmunization undergoing intrauterine transfusions. Ultrasound Obstet Gynecol 23:428-431

76. Bajoria R, Wee LY, Anwar S et al (1999) Outcome of twin pregnancies complicated by single intrauterine death in relation to vascular anatomy of the monochorionic placenta. Hum Reprod 14:2124-2130

77. Hack KEA, Derks JB, Elias SG et al (2008) Increased perinatal mortality and morbidity in monochorionic versus dichorionic twin pregnancies: clinical implications of a large Dutch cohort study. BJOG 115:58-67

78. Lopriore E, Stroeken H, Sueters M et al (2008) Term perinatal mortality and morbidity in monochorionic and dichorionic twin pregnancies: a retrospective study. Acta Obstetricia et Gynecologica 87:541-545

79. van Heteren CF, Nijhuis JG, Semmekrot BA et al (1998) Risk for surviving twin after fetal death of co-twin in twin-twin transfusion syndrome. Obstet Gynecol 92:215-219

80. Glenn O, Norton M, Goldstein RB et al (2005) Prenatal diagnosis of polymicrogyria by fetal magnetic resonance imaging in monochorionic cotwin death. J Ultrsound Med 24:711-716

81. Jelin AC, Norton ME, Bartha AI et al (2008) Intracranial magnetic resonance imaging findings in the surviving fetus after spontaneous monochorionic cotwin demise. Am J Obstet Gynecol 199(398):e391-e395

82. Righini A, Salmona S, Bianchini E et al (2004) Prenatal magnetic resonance imaging evaluation of ischemic brain lesions in the survivors of monochorionic twin pregnancies: report of 3 cases. J Comput Assist Tomogr 28:87-92

83. Righini A, Kustermann A, Parazzini C et al (2007) Diffusionweighted magnetic resonance imaging of acute hypoxicischemic cerebral lesions in the survivor of a monochorionic twin pregnancy: case report. Ultrasound Obstet Gynecol 29:453-456

84. Hoffman C, Weisz B, Gindes L et al (2009) Diffusion MRI findings in monochorionic twin pregnancies after intra-uterine fetal death. In: Abstracts of the American Institute of Ultrasound in Medicine meeting, New York

85. Feldstein VA (2002) Understanding twin-twin transfusion syndrome: role of Doppler ultrasound. Ultrasound Q 18:247254

86. Graef C, Ellenrieder B, Hecher K et al (2006) Long-term neurodevelopmental outcome of 167 children after intrauterine laser treatment for severe twin-twin transfusion syndrome. Am J Obstet Gynecol 194:303-308

87. Haverkamp F, Lex C, Hanisch C et al (2001) Neurodevelopmental risks in twin-to-twin transfusion syndrome: preliminary findings. Eur J Paediatr Neurol 5:21-27

88. Lenclen R, Paupe A, Ciarlo G et al (2007) Neonatal outcome in preterm monochorionic twins with twin-to-twin transfusion syndrome after intrauterine treatment with amnioreduction or fetoscopic laser surgery: comparison with dichorionic twins. Am J Obstet Gynecol 196(450):e451-e457

89. Lopriore E, Middeldorp JM, Sueters M et al (2007) Long-term neurodevelopmental outcome in twin-to-twin transfusion syndrome treated with fetoscopic laser surgery. Am J Obstet Gynecol 196(231):e231-e234 
90. Pharoah PO, Price TS, Plomin R (2002) Cerebral palsy in twins: a national study. Arch Dis Child Fetal Neonatal Ed 87:F122-F124

91. Quarello E, Molho M, Ville Y (2007) Incidence, mechanisms, and pattern of fetal cerebral lesions in twin-to-twin transfusion syndrome. J Matern Fetal Neonatal Med 20:589-597

92. Rossi AC, D'Addario V (2008) Laser therapy and serial amnioreduction as treatment for twin-twin transfusion syndrome: a metaanalysis and review of literature. Am J Obstet Gynecol 198:147-152

93. Hikino S, Ohga S, Kanda T et al (2007) Long-term outcome of infants with twin-to-twin transfusion syndrome. Fetal Diagn Ther 22:68-74

94. Hu LS, Caire JT, Twickler DM (2006) MR findings of complicated mulifetal gestations. Pediatr Radiol 36:76-81

95. Kline-Fath BM, Calvo-Garcia MA, O'Hara SM et al (2007) Twin-twin transfusion syndrome: cerebral ischemia is not the only fetal MR imaging finding. Pediatr Radiol 37:47-56

96. Manganaro L, Perrone A, Savelli S et al (2007) Evaluation of normal brain development by prenatal MR imaging. Radiol Med 112:444-455

97. Kasprian G, Brugger PC, Weber $M$ et al (2008) In utero tractography of fetal white matter development. Neuroimage 43:213-224

98. Jiang S, Xue H, Counsell S et al (2009) Diffusion tensor imaging (DTI) of the brain in moving subjects: application to in-utero fetal and ex-utero studies. Magn Reson Med 62:645-655

99. Kok RD, van den Bergh AJ, Heerschap A et al (2001) Metabolic information from the human fetal brain obtained with proton magnetic resonance spectroscopy. Am J Obstet Gynecol 185:1011-1015

100. Fenton BW, Lin C, Macedonia C et al (2001) The fetus at term: in utero volume-selected proton MR spectroscopy with a breathhold technique - a feasibility study. Radiology 219:563-566

101. Heerschap A, Kok RD, van den Berg PP (2003) Antenatal proton MR spectroscopy of the human brain in vivo. Child's Nerv Syst 19:418-421

102. Girard N, Fogliarini C, Viola A et al (2006) MRS of normal and impaired fetal brain development. Eur J Radiol 57:217-225

103. Hykin J, Moore R, Duncan K et al (1999) Fetal brain activity demonstrated by functional magnetic resonance imaging. Lancet 354:645-646

104. Moore RJ, Vadeyar S, Fulford J et al (2001) Antenatal determination of fetal brain activity in response to an acoustic stimulus using functional magnetic resonance imaging. Hum Brain Mapp 12:94-99

105. Fulford J, Vadeyar SH, Dodampahala SH et al (2004) Fetal brain activity and hemodynamic response to a vibroacoustic stimulus. Hum Brain Mapp 22:116-121

106. Jardri R, Pins D, Houfflin-Debarge V et al (2008) Fetal cortical activation to sound at 33 weeks of gestation: a functional MRI study. Neuroimage 42:10-18
107. Fulford J, Vadeyar SH, Dodampahala SH et al (2003) Fetal brain activity in response to a visual stimulus. Hum Brain Mapp 20:239-245

108. Zaharchuk G, Busse RF, Rosenthal G et al (2006) Noninvasive oxygen partial pressure measurement of human body fluids in vivo using magnetic resonance imaging. Acad Radiol 13:10161024

109. Rousseau F, Glenn O, Iordanova B et al (2005) A novel approach to high resolution fetal brain MR imaging. Med Image Comput Comput Assist Interv Int Conf Med Image Comput Comput Assist Interv 8:548-555

110. Jiang S, Xue H, Glover A et al (2007) MRI of moving subjects using multislice snapshot images with volume reconstruction (SVR): application to fetal, neonatal, and adult brain studies. IEEE Trans Med Imaging 26:967-980

111. Rousseau F, Glenn OA, Iordanova B et al (2006) Registrationbased approach for reconstruction of high-resolution in utero fetal MR brain images. Acad Radiol 13:1072-1081

112. Kim K, Habas PA, Rousseau F et al (2009) Intersection based motion correction of multi-slice MRI for 3D in utero fetal brain image formation. IEEE Transactions on Medical Imaging: In Press

113. Habas PA, Kim K, Rousseau F et al (2008) Atlas-based segmentation of the germinal matrix from in utero clinical MRI of the fetal brain. Med Image Comput Comput Assist Interv Int Conf Med Image Comput Comput Assist Interv 11:351-358

114. Habas PA, Kim K, Rousseau F et al (2009) A spatio-temporal atlas of the human fetal brain with application to tissue segmentation. Medical Image Computing and ComputerAssisted Intervention, LNCS 5761:289-296

115. Habas PA, Kim K, Chandramohan D et al (2009) Statistical model of laminar structure for atlas-based segmentation of the fetal brain from in-utero MR images. Medical Imaging 2009: Image Processing, Proc SPIE 7259, 725917. doi:10.1117/12. 812425

116. Habas PA, Kim K, Rodriguez-Carranza CE et al (2009) Abnormal sulcal formation in fetuses with ventriculomegaly identified by surface curvature mapping from motion-corrected clinical MRI. 15th Annual Meeting of the Organization for Human Brain Mapping, San Francisco

117. Rodriguez-Carranza CE, Mukherjee P, Vigneron D et al (2008) A framework for in vivo quantification of regional brain folding in premature neonates. Neuroimage 41:462-478

118. Chandramohan D, Habas PA, Kim K et al (2009) Cortical thickness mapping of the human fetal brain in utero from motion-corrected clinical MRI: preliminary results. 15th Annual Meeting of the Organization for Human Brain Mapping, San Francisco

119. Glenn OA, Barkovich J (2006) Magnetic resonance imaging of the fetal brain and spine: an increasingly important tool in prenatal diagnosis: part 2. AJNR 27:1807-1814 